\title{
Community Gardening Activities and Their Effects on Mental Health of Residents
}

\author{
Hye Sook Jang, Gyung Mee Gim, Sun-Jin Jeong*, and Jae Soon Kim \\ National Institute of Horticultural and Herbal Science, Rural Development Administration, Wanju-gun 55365, Korea
}

\section{ABSTRACT}

This study was conducted to find out the effects of plant cultivation activities in the village gardening program hosted by Gyeonggi-do on the psychology and physiology of participants. This study conducted a survey on 20 villagers aged $57.70 \pm 9.23$ on average and collected their saliva before Session 1 and after the final Session 10. The experiment was conducted by carrying out the village gardening program once a week for total 10 weeks. Psychological assessment was conducted by measuring the level of plant cultivation experience, four elements (repose, fascination, coherence, legibility) of the Perceived Restorativeness Scale (PRS) and stress levels, and also conducting the Wilcoxon paired signed ranks test. As the result of comparatively analyzing the saliva collected before and after the program, the total cortisol level, which is a stress hormone, decreased with statistical significance after the program $(t=14.521, p \alpha .001)$. The level of plant cultivation activities increased with statistical significance after the program, and the PRS increased with statistical significance in the three elements of repose, fascination and legibility excluding coherence. In addition, as the result of examining the change in the stress level of participants with the sum of all item scores, it was found that the stress level decreased with statistical significance ( $\not<.05)$ from 17.65 points to 15.30 points after the program. Hence, plant cultivation activities in the village community have positive effects such as attention restoration or stress relief. In addition, the activities can also contribute to mental connection and healthcare of residents.

Keywords: coherence, PRS, repose, stress hormone

\section{Introduction}

People today have failed to adjust to artificial environment in their living conditions and have been exposed to environmental stress such as excessive noise, light and find dust. Those exposed to such environmental stress are vulnerable to diseases, and excessive stress is likely to cause mental illnesses like depression and panic disorder as well as physical illnesses like cancer or cardiovascular disorders (Matz et al., 2014; Mckenzie-Mohr et al., 1995). As it has become difficult to maintain a nature-friendly life due to the artificial urban environment, city people that are ex- posed to physically and mentally complex and diverse diseases are suffering from all kinds of stress, mental instability and health problems due to environmental pollution (Kim et al., 2013). Chronic stress empowers sympathetic nerves that represent tension and stress, discharging excessive stress hormones like cortisol and thereby lowering immunity (Hadley and Levine, 2006).

However, the effect of nature or green areas on stress relief is a general outcome of various stimulations through the five senses, not fragmentary stimulations (Miyazaki et al., 2011). People working in an environment where there is a park nearby even though they are not involved in direct

This study was supported by the 2019 Horticultural and Herbal Science Program of the National Institute of Horticultural and Herbal Science of the Rural Development Administration (PJ01137604).

Received: May 29, 2019, Revised: June 23, 2019, Accepted: July 15, 2019

First author: Hye Sook Jang, jhs915@korea.kr, (10) https://orcid.org/0000-0003-3011-8694

*Corresponding author: Sun-Jin Jeong, sunjin75@korea.kr, (10) https://orcid.org/0000-0001-6279-9733 
plant activities tend to have lower satisfaction or stress than others, which implies that indirect experience of nature also has a positive effect on human psychology (Shin, 2003). Moreover, participants in plant cultivation programs show an increase in brain activity, decrease stress hormones such as cortisol (Jang et al., 2018a, 2018b), and higher enjoyment, stability, confidence, and interest and understanding about plants, thereby showing positive effects of plant cultivation activities (Kim, 2001; Shin et al., 2007).

Recently, there is more and more evidence that activities in nature have a positive relation to individual health (Hine et al., 2008), and the attention restoration theory (ART) by Kaplan and Kaplan (1989) that explains various benefits of the natural environment shows how much positive effect contact with nature has on humans. According to the theory, human beings have directed attention in which they are likely to be exhausted in urban life, and the simplest way to recover from such exhaustion is by involuntary attention in which they can be provided with such opportunity from natural elements. Natural elements have been considered to improve cognitive and emotional resilience of humans and provide psychological comfort and stability (Hartig et al., 1991; Kaplan, 1995). Nature provides an opportunity for restoration just by touching or looking. Gardening activities with others improve creativity and self-expression (Relf, 1981), and accessible village gardens can activate the community among neighbors. Thus, the Rural Development Administration (RDA) has been carrying out a gardening project with residents in front of alleys, vacant lots and shopping centers since 2015. The scope of village gardens to encounter nature in daily life is expanded to the public sector where people can communicate with neighbors from personal space (RDA, 2015), and community gardens in the village are perceived as an alternative to be in contact with nature in the city (Jeffrey et al., 2009).

Therefore, this study is conducted to examine the effect of village gardening programs on stress relief of villagers. Moreover, it is to verify the effect of the plant cultivation and healing program, which can help increase communication among neighbors and reduce stress, through physiological assessment using salivary cortisol (stress indicator) and psychological assessment using a survey.

\section{Research Methods}

\section{Selection of the subjects}

To determine the effects of the plant cultivation program on stress relief and psychological stability of villagers, this study collected saliva and conducted a survey on total 20 subjects aged $57.70 \pm 9.23$ on average at the village halls and community service centers in Suwon, Gyeonggi. We sufficiently explained the research objectives, measurement items and methods to the participants and selected only those who signed the consent form with voluntary will to participate in the experiment. Saliva collection and the survey took place twice at the same time, once in Session 1 of the indoor/outdoor plant cultivation program and Session 10 that is the last session (Choi et al., 2014). The program was carried out once a week for total 10 weeks (Table 1), with each session lasting 90 minutes ( \pm 10 minutes). The participants were to abstain from drinking alcohol from 2 days before the measurement, and also from consuming any food or beverage that may stimulate the saliva such as coffee, green tea and caffeine from 1 hour before the test.

\section{Materials and activities of the village gardening program Sessions 1 through 10}

The materials for the experiment were succulent plants, preserved flowers and chrysanthemums. The participants were to study the method of maintaining and managing the village gardens through plant activities, gardening and village garden trips. The program also included advanced (or intensive) learning and self-expression activities for sustainability of community plant activities (Fig. 1). The activities were carried out with a specialized instructor and an assistant instructor, consisting of one main host (Horticultural Therapist Registered for Well-being, Urban Agriculture Manager, Craftsman Floral Design, Craftsman Pressed Flower, Vocational Counselor) and one assistant (Horticultural Therapist Registered for Well-being, Craftsman Horticulture, Urban Agriculture Manager). The participants practiced and learned the process of creating community gardens in the region's green areas based on garden design education to cultivate the abilities to create gardens and solve problems 
through the program. Moreover, they were provided with education to improve problem solving skills through communication and cooperation in the program among teams grouped according to the relevance of education. To enhance the competencies of village gardeners, various activities based on theory and practice were carried out through garden management education by season, such as managing public open spaces and village gardens, guerilla gardening, and making safe and healthy natural fertilizers and pest control materials. Moreover, we also carried out a program to promote community friendship and understanding about the village garden creating method by exploring best practices.

\section{Tool for physiological assessment of participants}

\section{Saliva collection and analysis method using the Salivettes system}

Saliva was collected before and after all sessions of plant cultivation activities at the same time (Choi et al., 2014) because cortisol excretion of adults varies depending on time (Posener et al., 2000).

This study adopted the Salivettes system using cotton swabs for saliva collection. It is convenient to spit out and collect saliva in a certain container like a tube or bottle, but it is also likely to be easily contaminated. The Salivettes system used in the study can accurately measure salivary cortisol by collecting good quality saliva and minimizing contamination by hand or air.

For saliva collection, first, open the lid of the tube and expose the cotton stick inside the tube. Second, hold the tube upside down and drop the cotton stick inside the mouth, Third, gently hold the stick inside the mouth for about 5 minutes, and then put it back into the tube without touching it with hands. Fourth, seal the lid completely, and record the code number, date and time of collection of the participants. Fifth, put the collected saliva inside an icebox

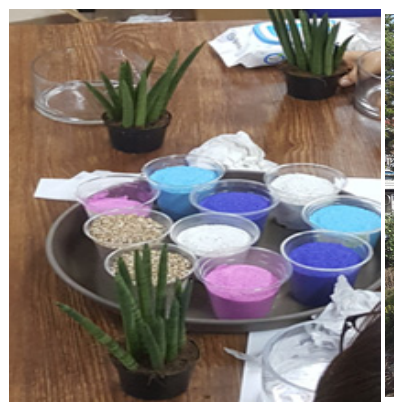

(A)

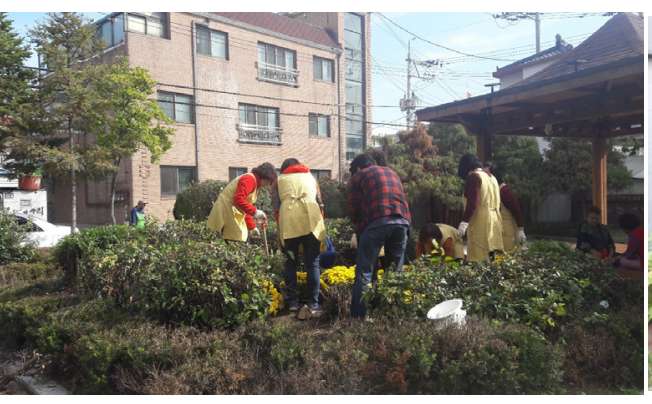

(B)

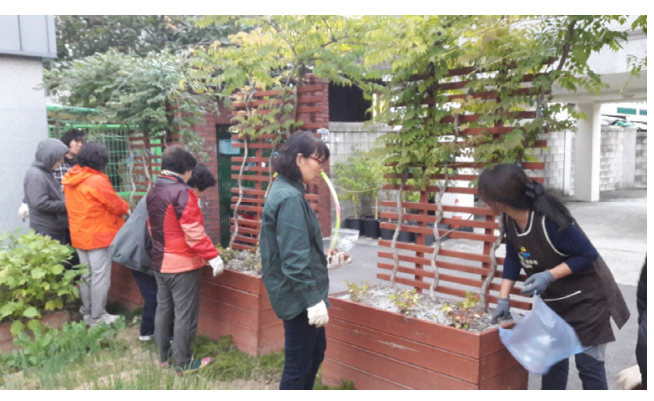

(C)

Fig. 1. Plant gardening activities in the village gardening program. Images of making mini gardens (A), planting chrysanthemums outside the building (B), and container gardening (C).

Table 1. Plant cultivating activities applied to the objects

\begin{tabular}{cl}
\hline Session & \multicolumn{1}{c}{ Plant cultivating activities program } \\
\hline 1 & Basic understanding of plants and making a terrarium with succulent plants \\
2 & Learning about succulent plants and planting \\
4 & Gardening 1- garden design and planting wildflowers \\
5 & Harvesting marigold flowers and making flower tea \\
6 & Gardening 2 - understanding the basics of garden maintenance and planting plants in pots \\
7 & Gardening 3 - understanding the physiology of fall-planted bulbs and planting practice \\
8 & Planting chrysanthemums outside the building \\
9 & Planting cauliflowers and chrysanthemums outside the building \\
10 & Making preserved flower frames and greeting cards \\
\hline
\end{tabular}


full of dry ice and freeze the specimen inside the freezer (Schwartz et al., 1998; Jang et al., 2018a). Salivary cortisol of the collected specimen was analyzed with the VERSA Max Microplate Reader (Molecular device, USA) using the ER HS SALIVARY CORTISOL kit (Salimetrics Inc, USA) reagent, and the unit of analysis is $\mu \mathrm{g} / \mathrm{dl}$. Higher salivary cortisol levels indicate increased stress reaction, and lower levels indicate decreased stress reaction.

\section{Tool for psychological assessment of participants}

The Korean version of the Perceived Restorativeness Scale (PRS), Perceived Stress Scale (PSS), and plant cultivation experience level were used as the tools for assessing psychological characteristics.

\section{Korean version of the Perceived Restorativeness Scale (PRS)}

This study used the Korean version of the PRS, which is based on 16 items developed by Kaplan and Kaplan (1989) to which 10 items were added by Hartig et al. (1997) and modified by Lee and Hyun (2003). The Korean version of the PRS is comprised of four factors such as 'repose', 'fascination', 'coherence' and 'legibility' as a measure to assess the restorative environment, and each item was rated on a 7-point Likert scale (1 point: strongly disagree, 7 points: strongly agree). The Cronbach's $\alpha$ of this study was .929 .

\section{Korean version of the Perceived Stress Scale (PSS)}

The PSS used in this study was the Korean version of the PSS (PSS-K) based on the PSS-10 developed by Cohen and Williamson (1988) and adapted by Baek (2009). The scale is comprised of 10 items, determining the scores of items responded by the participants that are added according to the grading table in four levels. The 10 items are comprised of two factors, which are negative experience related to stress and positive experience by coping resource. Higher total scores indicate higher level of perceived stress. Level 1 is analyzed as 'the state of normal stress in which the stress factor itself is not severe or the stress is accepted as good stress' if the total score is below 13 points; Level 2 is 13 points and higher as 'the state in which one is already affected by stress'; Level 3 is 17 points and higher as 'the state in which it is highly likely to be developed into a mental disease'; and Level 4 is 19 points and higher as 'the state in which one needs professional help'. Each item rated on a 5-point Likert scale (0 point: strongly disagree, 4 points: strongly agree). The Cronbach's $\alpha$ of this study was .897 .

\section{Level of plant cultivation experience of participants}

The level of plant cultivation activities is comprised of total 12 items rated on a 7-point Likert scale (Jang et al., 2018a; Jeong et al., 2019; RDA, 2017), and the scale consists of three sub-categories: four items in plant cultivation experience, four items in plant preference tendency, and four items in plant-related event, with higher scores indicating higher level of plant cultivation experience or perception. The Cronbach reliability test result of the tool in this study was $\alpha=.957$.

\section{Statistical analysis}

IBM SPSS ver. 25.0 was used in the statistical analysis of this study, and Cronbach's $\alpha$ was calculated for reliability analysis of the tools. The Wilcoxon paired signed ranks test was conducted for salivary cortisol, Korean version of the PRS (Lee, 2006; Lee and Hyun, 2003), PSS, and level of plant cultivation activities, and frequency analysis was conducted for sociodemographic characteristics.

\section{Results and Discussion}

\section{Sociodemographic background}

As a result of examining the general characteristics of the participants in village gardening plant cultivation activities, $15 \%$ of the participants were male and $85 \%$ were female; and $40 \%$ were in their $50 \mathrm{~s}, 40 \%$ were in their $60 \mathrm{~s}$ or older, and $20 \%$ were in their $40 \mathrm{~s}$. By education level, $60 \%$ were high school graduates, followed by college graduates $(20 \%)$ and elementary school graduates $(15 \%)$. By occupation, $73.7 \%$ were full-time homemakers, followed by office workers $(10.5 \%)$ and others $(15.8 \%)$. By average monthly household income, 20\% earned KRW 1.51-2.5 
million per month, followed by below KRW 1 million and KRW 1-1.5 million (15\%), KRW 2.51-4 million and above KRW 4 million (10\%).

\section{Change in cortisol levels as a stress hormone}

As a result of examining the change in cortisol levels of the participants before and after the program (Fig. 2), total cortisol level, which is a stress hormone), decreased from $0.104 \mu \mathrm{g} / \mathrm{dl}$ to $0.81 \mu \mathrm{g} / \mathrm{dl}$ after the program, showing a mean difference of $0.23 \mu \mathrm{g} / \mathrm{dl}(\mathrm{z}=2.048, p<.05)$ with statistical significance. This is consistent with the result that depression and cortisol of rehabilitants decreased after

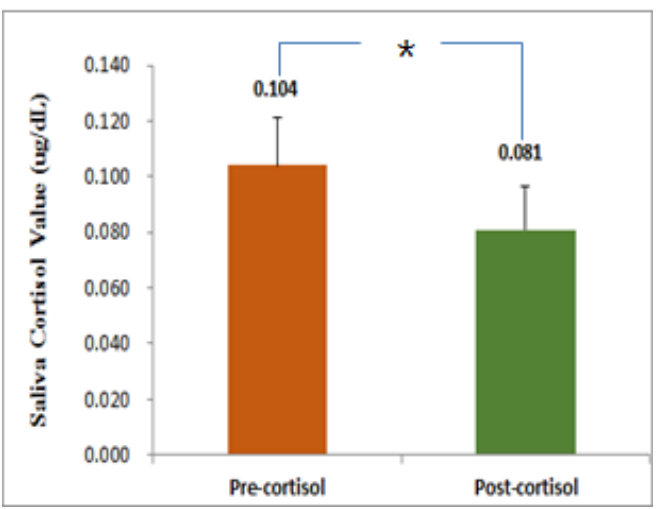

Fig. 2. Change in cortisol levels of subjects from pre- to post village gardening program. An asterisk denotes significance at $p<.05$. a horticultural therapy program (Lee et al., 2013) and that stress of parents of elementary school students decreased after participating in a plant cultivation program (Jang et al., 2018a), thereby supporting the research that plant cultivation activities can reduce stress

\section{Analysis of psychological characteristics}

\section{Korean version of the Perceived Restorativeness Scale}

As a result of determining the change according to the four factors of the PRS before and after participating in the program, it was found that the three factors (repose, fascination, legibility) excluding coherence increased after the program with statistical significance (Table 2). The attention restoration theory by Kaplan and Kaplan (1989) that mental and psychological fatigue accumulated by conscious activities of human beings can be relieved by nature supports the results of this study that showed an increase in repose.

\section{Perceived Stress Scale-K (PSS-K)}

As a result of examining the change in the stress level of the participants before and after the program by adding up the scores of all items, it was found that the stress level decreased from 17.65 points to 15.30 points after the program with statistical significance $(p<.05)$ (Table 3). Based on the PSS-K analysis method, this result can be analyzed

Table 2. Changes in the Perceived Restorativeness Scale of the village gardening program participants

\begin{tabular}{lcccc}
\hline \multirow{2}{*}{ Variance } & \multicolumn{2}{c}{$\mathrm{M} \pm \mathrm{SD}$} & $\mathrm{z}$ & $p$ \\
\cline { 2 - 5 } & Before & After & -3.287 & $.001^{* * *}$ \\
Repose & $4.182 \pm 1.13$ & $5.485 \pm 1.40$ & -2.800 & $.005^{* *}$ \\
Fascination & $4.238 \pm 1.40$ & $5.413 \pm 1.03$ & -0.835 & $.404^{\text {NS }}$ \\
Coherence & $5.171 \pm 1.30$ & $5.450 \pm 1.42$ & -2.371 & $.018^{*}$ \\
Legibility & $4.800 \pm 1.51$ & $5.867 \pm 1.11$ & \\
\hline
\end{tabular}

Note. 7-point Likert scale was used, where $1=$ strongly disagree, $7=$ strongly agree.

${ }^{\mathrm{NS}}$ Non-significant, ${ }^{*} p<.05,{ }^{* *} p<.01,{ }^{* * *} p<.001$ by Wilcoxon paired signed-rank test $(\mathrm{n}=20)$.

Table 3. Changes in the level of stress of the village gardening program participants

\begin{tabular}{|c|c|c|c|c|}
\hline \multirow{3}{*}{ Stress level } & \multicolumn{2}{|c|}{$\mathrm{M} \pm \mathrm{SD}$} & \multirow{2}{*}{ Z } & \multirow{2}{*}{$p$} \\
\hline & Before & After & & \\
\hline & $17.65 \pm 5.80$ & $15.30 \pm 5.23$ & -2.401 & $.016^{*}$ \\
\hline
\end{tabular}

Note. 5 -point Likert scale was used, where $0=$ strongly disagree; $4=$ strongly agree.

$*^{*} p .05$ by Wilcoxon paired signed-rank test $(\mathrm{n}=20)$. 
as 'the state in which it is highly likely to be developed into a mental disease' for 17 points and higher to 'the state in which one is already affected by stress' for 15 points and higher. Thus, this result, which represents the stress level reduction effect of plant cultivation activities, is useful in lowering stress that is considered a significant problem for people today. The findings by Urich (1984) and Cimprich (1993) that use of nature affects stress relief, positive emotions, emotional change and treatment of diseases tend to be in line with the result of this study that the stress level decreased after participating in plant cultivation activities. Moreover, the reduction of stress by nature or green areas like plant cultivation is a general outcome of various stimulations using the five senses (Miyazaki et al., 2011).

\section{Level of plant cultivation experience}

As a result of examining the changes in plant cultivation experience, plant preference tendency, and plant-related event that are the three elements about thoughts or experiences about plants before and after participating in the program, it was found that the levels of two elements except plant cultivation experience increased after the program with statistical significance (Table 4). The findings by Jang et al. (2016), which showed that there was statistical significance in the item of "willingness to invest in plant purchase" among the loyalty items after experiencing indoor gardening, are similar to the results of this study showing positive effects of directly participating in plant activities. Participation in plant cultivation not only increases preference of plants or brings back good memories about plants, but also gives confidence, stability and enjoyment as well as psychological satisfaction, while also increasing interest and understanding about plants and providing positive effects (Kim, 2001; Shin et al., 2007).

\section{Conclusion}

To determine the effects of village gardening plant cultivation activities hosted by Gyeonggi-do on psychology and physiology of participants, this study conducted a survey on 20 villagers aged $57.70 \pm 9.23$ on average and collected their saliva before Session 1 and after the final Session 10. The experiment was performed by carrying out the village gardening program once a week for total 10 weeks, 90 minutes each. Psychological assessment was conducted by measuring the level of plant cultivation experience, four elements (repose, fascination, coherence, legibility) of the PRS and stress levels, and also conducting the Wilcoxon paired signed ranks test. As a result of comparatively analyzing the saliva collected before and after the program, the total cortisol level, which is a stress hormone, decreased with statistical significance after the program $(\mathrm{t}=14.521$, $p<.001)$. The result of examining the level of plant cultivation activities and PRS showed that the level of plant cultivation activities increased with statistical significance after the program, and the PRS increased with statistical significance in the three elements of repose, fascination and legibility excluding coherence. Moreover, as a result of examining the change in the stress level of participants with the sum of all item scores, it was found that the stress level decreased with statistical significance $(p<.05)$ from 17.65 points to 15.30 points after the program. This indicates that the stress level decreased from 'the state in which it is highly likely to be developed into a mental disease' to 'the state in which one is already affected by stress', thereby proving that the program had effect on relieving stress of participants. Ulrich et al. (1991) conducted physiological assessment after showing a video of the natural environment and proved that people showed higher

Table 4. Changes in the level of plant growing activities of the village gardening program participants

\begin{tabular}{lcccccc}
\hline \multirow{2}{*}{ Factor } & \multicolumn{2}{c}{$\mathrm{M} \pm \mathrm{SD}$} & & \multicolumn{2}{c}{} & \multirow{2}{*}{ Cronbach's $\alpha$} \\
\cline { 2 - 3 } & Before & After & & & \\
\hline Experience of growing plants & $5.10 \pm 1.47$ & $5.46 \pm 0.96$ & & -1.737 & $.082^{\mathrm{NS}}$ & .916 \\
Preference in plants and gardening & $4.93 \pm 1.32$ & $5.54 \pm 0.99$ & -2.566 & $.010^{* *}$ & .898 \\
Motivation for gardening & $5.00 \pm 1.15$ & $5.59 \pm 0.95$ & -2.349 & $.019^{*}$ & .881 \\
\hline
\end{tabular}

Note. 7 -point Likert scale was used, where $1=$ strongly disagree; $7=$ strongly agree.

${ }^{\mathrm{NS}}$ Non-significant, $* p<.05, * * p<.01$ by Wilcoxon paired signed-rank test $(\mathrm{n}=20)$. 
stress recovery rates than the urban environment even without directly participating in plant activities. The study results show that plant cultivation activities in the village community have positive effects such as attention restoration or stress relief and can contribute to mental connection and healthcare of residents through community activities. Moreover, village gardening community projects involving settlers from other regions will provide an opportunity for the residents to mutually interact with one another and reduce conflicts among themselves.

\section{References}

Baek, Y.M. 2009. Korean version of the perceived stress scale-10: Development of the scale and exploring the effects of perceived stress on memory. Doctoral dissertation, Seoul National University, Seoul, Korea.

Choi, S.H., I.S. See, I.J. Song, O.J. Kwon, K.O. Park, H.J. Hong, K.K. Sung, and S.K. Lee. 2014. Method of saliva collection for salivary cortisol measurement. Korean J. Orient. Physiol. Pathol. 28(2):223-232. https://doi.org/10.15188/kjopp.2014.04.28.2.223

Cimprich, B.E. 1993. Development of an intervention to restore attention in cancer patients. Cancer Nurs. 16(2):83-92.

Cohen, S. and G.M. Williamson. 1988. Perceived stress in a probability sample of the United States. In: S. Spacapan and S. Oskamp (Eds), The Social Psychology of Health: Claremont symposium on applied social psychology (pp. 31-67). Newbury Park, CA: Sage.

Hadley, M.E. and J.E. Levine. 2006. Endocrinology (6th ed.). Upper Saddle River, NJ: Prentice Hall.

Hartig, T., F.G. Kaiser, and P.A. Bowler. 1997. Further development of a measure of perceived environmental restorativeness (Working Paper No. 5). Gǟvle, Sweden: Uppsala University, Institute for Housing Research.

Hartig, T., M. Mang, and G.W. Evans. 1991. Restorative effect of natural environment experiences. Environ. Behav. 23(1):3-26. https://doi.org/10.1177/0013916591231001

Hine, R., J. Peacock, and J. Pretty. 2008. Care farming in the UK: Evidence and opportunities. Report for the
National Care Farming Initiative (UK). Colchester, UK: University of Essex.

Jang, H.S., G.M. Gim, S.J. Jeong, and J.S. Kim. 2018a. Effects of plant cultivating activity for reducing parental stress. J. People Plants Environ. 21(3):203-211. https://doi.org/10.11628/ksppe.2018.21.3.203

Jang, H.S., G.M. Gim, S.J. Jeong, and J.S. Kim. 2018 b. Neurophysiological changes in elementary school parents after plant cultivation activity. J. People Plants Environ. 21(5):351-367. https://doi.org/10.11628/ksppe.2018.21.5.351

Jang, H.S., K.J. Kim, E.H. Yoo, and H.H. Jung. 2016. Impact of indoor-garden in the public building of lounge to the psychological effect of resident. J. Korean Soc. People Plants Environ. 19(3):167-174. https://doi.org/10.11628/ksppe.2016.19.3.167

Jeffrey, H., J.M. Johnson, and L.J. Lawson. 2009. Greening cities, growing communities: Learning from Seattle's urban community gardens. Washington, DC: Landscape Architecture Foundation.

Jeong, S.J., G.M. Gim, J.S. Kim, H.S. Jang, and G.W. Lee. 2019. Analysis of preference of environmental image for the increase and promotion of rose consumption J. People Plants Environ. 22(1):53-63. https://doi.org/10.11628/ksppe.2019.22.1.053

Kaplan, R. and S. Kaplan. 1989. The experience of nature: A psychological perspective. New York, NY: Cambridge University Press.

Kaplan, S. 1995. The restorative benefits of nature: Toward an integrative framework. J. Environ. Psychol. 15(3): 169-182. https://doi.org/10.1016/0272-4944(95)90001-2

Kim, J.H., S.Y. Lee, and Y.H. Yoon. 2013. The effects of urban stream landscape on psychological relaxation of university students: Focused on Chenggyencheon, Seoul, Korea. Seoul Stud. 14(1):169-182.

Kim, S.Y. 2001. Effect of horticultural therapy on the functional rehabilitation in hemiplegic patients after stroke. Master's thesis, Konkuk University, Seoul, Korea.

Lee, S.H. 2006. The emotion-improving effects of the index of greenness: focusing on fascination model and restorative environment model. Doctoral dissertation, ChungAng University, Seoul, Korea.

Lee, S.H. and M.H. Hyun. 2003. The factor structure of 
the Korean version of the perceived restorativeness scale (PRS). Korean J. Health Psychol. 8(2):229-241.

Lee, S.M., J.H. Moon, S.J. Jeong, and Y.J. Lee. 2013. Effects of horticultural therapy program focusing on cultivating activities for prisoners scheduled to be released on depression and salivary cortisol. J. Korean Soc. People Plants Environ. 16(4):173-180. https://doi.org/10.11628/ksppe.2013.16.4.173

Matz, C.J., D.M. Stieb, K. Davis, M. Egyed, A. Rose, B. Chou, and O. Brion. 2014. Effects of age, season, gender and urban-rural status on time-activity: Canadian Human Activity Pattern Survey 2 (CHAPS 2). Int. J. Environ. Res. Public Health 11(2):2108-2124. https://doi.org/10.3390/ijerph110202108

Mckenzie-Mohr, D., L.S. Nemiroff, L. Beers, and S. Desmarais. 1995. Determinants of responsible environmental behavior. J. Soc. Issues 51(4):139-156. https://doi.org/10.1111/j.1540-4560.1995.tb01352.x

Miyazaki, Y., B.J. Park, and J. Lee. 2011. Nature therapy. In: M. Osaki, A. Braimoh, and K. Nakagami (Eds.), Designing our future: Local perspectives on bioproduction, ecosystems and humanity (pp. 407-412). Tokyo, Japan: United Nations University Press. https://doi.org/10.18356/66aa5f41-en

Posener, J.A., C. DeBattista, G.H. Williams, H.C. Kraemer, B.M. Kalehzan, and A.F. Schatzberg. 2000. 24-hour monitoring of cortisol and corticotropin secretion in psychotic and nonpsychotic major depression. Arch. Gen. Psychiatry 57(8):755-760.

Relf, P.D. 1981. The use of horticulture in vocational rehabilitation. J. Rehabil. 47(3):53-56.

Rural Development Administration. 2015. Guidebook of village garden. Wanju, Korea: RDA.

Rural Development Administration. 2017. Technology dissemination manual of preventative oriented type agro-healing (pp. 183-184). Wanju, Korea: RDA.

Schwartz, E.B., D.A. Granger, E.J. Susman, M.R. Gunnar, and B. Laird. 1998. Assessing salivary cortisol in studies of child development. Child Dev. 69(6):1503-1513.

Shin, W.S. 2003. Wilderness use and benefits: A literature review. J. Korean Inst. For. Recreat. 7(2):1-7.

Shin, W.S., P.S. Yeoun, and J.H. Lee. 2007. The impact that a forest experience influences on a human mental state stability. J. Korean Inst. For. Recreat. 11(3):37-43.

Ulrich, R.S. 1984. View through a window may influence recovery from surgery. Science 224(4647):420-421.

Ulrich, R.S., R.F. Simons, B.D. Losito, E. Fiorito, M.A. Miles, and M. Zelson. 1991. Stress recovery during exposure to natural and urban environments. J. Environ. Psychol. 11(3):201-230. 